\title{
Interactive \& Informative Digital Board using Raspberry PI
}

\author{
M. Bala Nagammal ${ }^{1}$, S. Nilavarasi ${ }^{2}$, M. Priyanka ${ }^{3}$, Prof. Mr. A. John Paul Antony, M.E. ${ }^{4}$ \\ Kamaraj College of Engineering and Technology, Virudhunagar ${ }^{1,2,3,4}$
}

\begin{abstract}
Informative system is a most important thing which provides up-to-date information without much effort. In the normal notice board, a separate person is required to take care of this notices, but our main aim is to provide green environment and to provide ease of use. This project is about advanced wireless notice board. The project is built around ARM controller raspberry-pi which is heart of the system. In this system, the user may interact with the system and can get the information from the Informative system via the mobile application. The admin will provide the information, and the user can view the information from the system by interacting with the system through mobile application. This informative system was developed using the open source software's and this makes informative system cheaper when compared to the other system. This interactive and informative system can be used for commercial purposes such as shopping malls, Railway stations, airports and also for the Educational purposes. This informative System uses internet connection for client and server communication which makes communication faster.
\end{abstract}

Keywords: raspberry-pi, Interactive and Informative Digital Board, mobile application.

\section{INTRODUCTION}

In today's world people want to get easy access to the information. To make this happen we can have the several ways to disperse the information within the organization, but dispersing manually is not that much easy. It can be made easier by providing an automatic way. One of the automatic ways to disperse the information is Informative system which will pass the information quickly once it was uploaded. Nowadays people prefer wireless connection because they interact with the people easily and it requires less time. In this Digital board we can interact using the voice commands and the system will work according to the user commands.

\subsection{Internet of Things}

The Internet of Things (IoT) is a system of interrelated computing devices, mechanical and digital machines, objects, and the ability to transfer data over a network without requiring human-to-human or human-to-computer interaction. The IoT allows objects to be sensed and/or controlled remotely across existing network infrastructure, creating opportunities for more direct integration of the physical world into computer-based systems, and resulting in improved efficiency, accuracy and economic benefit in addition to reduced human intervention.

\subsection{Raspberry PI}

The Raspberry Pi is a series of credit card-sized singleboard computers developed in the United Kingdom by the Raspberry Pi Foundation to promote the teaching of basic computer science in schools and in developing countries. The original model became far more popular than anticipated, selling outside of its target market for uses such as robotics. Peripherals (including keyboards, mice and cases) are not included with the Raspberry Pi.

Some accessories however have been included in several official and unofficial bundles.

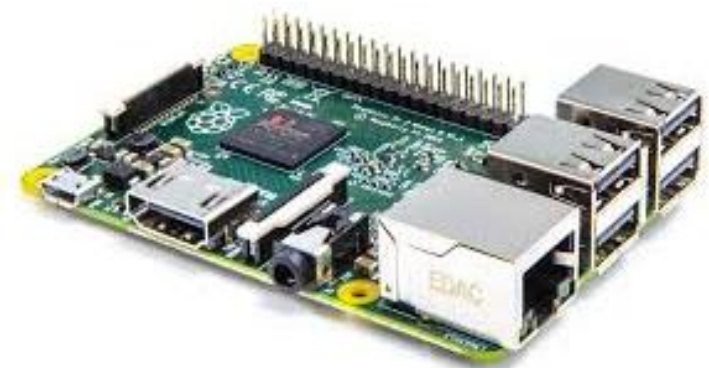

Fig1: Raspberry PI

\section{EXISTING SYSTEM}

In this modern world, everything was replaced with the latest technologies but this information passing is still happening with the manual paper work. This is mainly because of the high cost digital notice boards .To overcome this cost problem this system was developed with the open source software's. This system makes the manual paper works into the digitalized form. The main drawback in the existing system is the high cost and static display of information. The main objective of this system is to develop the dynamic / interactive board with the Low cost.

This application can be used in the different areas like Educational institute, commercial purposes like shopping malls, Railway stations, Banking Sectors etc. In the commercial application this can be used to display the advertisements, View the information which is requested by the user. By using the LCD display along with the 
Raspberry PI which will act as the processor, the information can be processed and displayed in the display. According to the user's request the server will provide the response in the display.

The open source software's such as xampp server, raspbian os, Netbeans, android studio was used to develop the user's view and the application.

\section{PROPOSED SYSTEM}

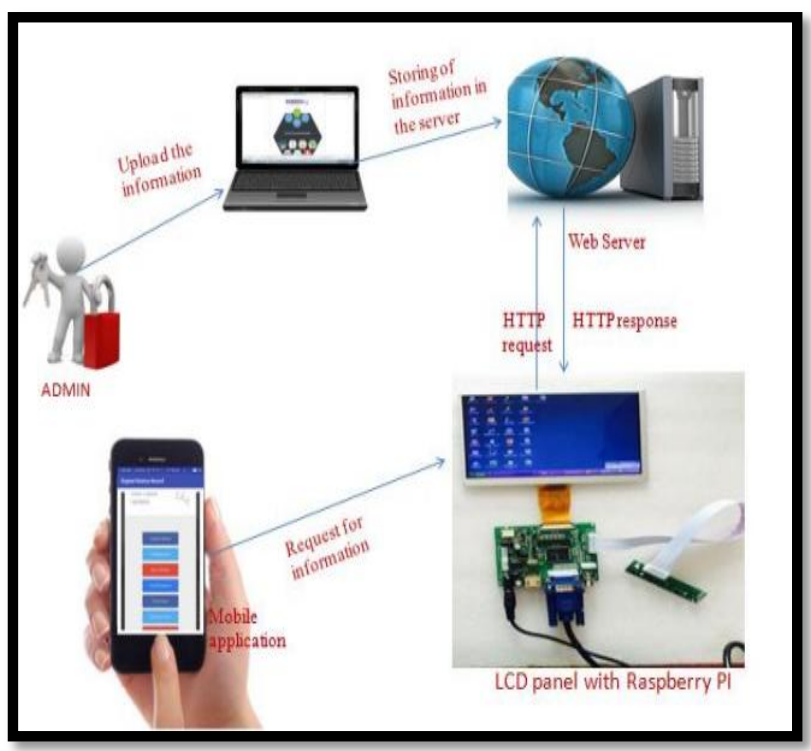

Fig 2: Proposed System Architecture

\section{1: Created Applications:}

In this circular notification web page, we split it into two parts: Admin page and Control page.

\section{Admin Page}

In this Admin page, the home page has the services such as,

- Home

- Login

- Contact

- Services

And the Notification tags such as,

- First year

- Second year

- Third year

- Final year

- Important

- Placement

- General

\section{Control Page}

To control the board and to make the digital board interactive the application can be used .The user may use the application to control the board. And user can view the notification of his selected year and category. The user can login to the application and can access the service with the application.
The application is developed using the PHP and it is converted into the mobile application using the android studio. The application can be used to interact with the board. Through this application the user can control the web page.

\section{2:Architecture Followed:}

It is a concept named Master-Slave relationship. After admin or staff uploads a update into the Web server, the student or any other user can view the Uploaded updates from their device. And then, they can control or view the web page through their mobile. Here the student or user's device will act as a "Slave" or "Client" and the admin or staff inserted database will act as a "Master" or "Server". The Architecture of client and server will be as follows:

Here

Client $\rightarrow$ Student or User device

Server $\rightarrow$ Admin of Staff database

Request by client $\rightarrow$ Requesting a page by student or user. A client is a piece of computer hardware or software that accesses a service made available by a server. The server is often (but not always) on another computer system, in which case the client accesses the service by way of a network. The term applies to the role that programs or devices play in the client-server model.

The client can access the board and get the information immediately using the display $\mathrm{p}$ age. The client server communication is carried out through the medium.

A client is part of a client-server model, which is still used today. Clients and servers may be computer programs run on the same machine and connect via inter-process communication techniques. Combined with Internet sockets, programs may connect to a service operating on a possibly remote system through the Internet protocol suite. Servers wait for potential clients to initiate connections that they may accept.

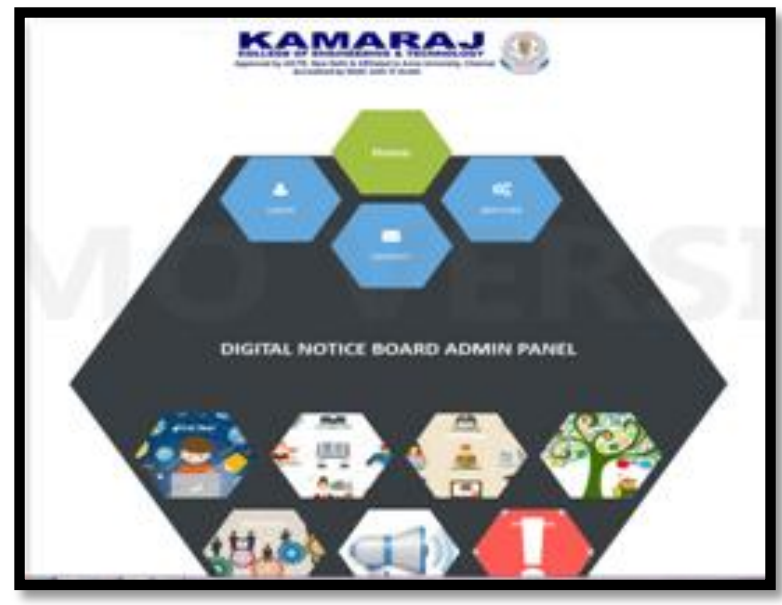

Fig 2.1: Master's uploading page

Fig 3.1 indicates the page which is accessed only by the authorized staff members to upload their updates.

Fig 3.2 indicates the client's mobile application which is used to control and view the updates posted by the $\operatorname{admin}($ Staff). 


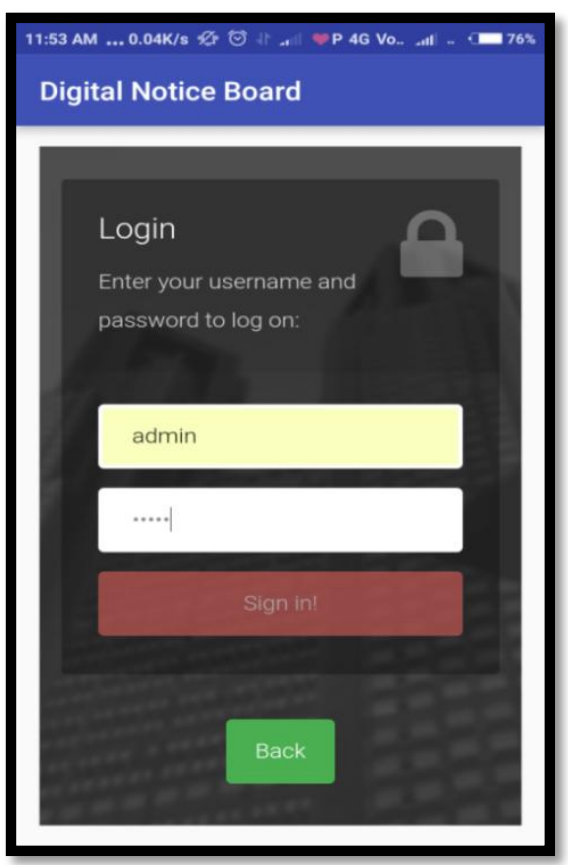

Fig 3.2: Client's Mobile application

\section{CONCLUSION}

The design of our UI is based upon PHP methodology, this UI will scale better than when compared to a HTML forms counterpart. The user's browser is responsible for running the code to generate the UI, perform browserbased animations, and receive the information. The Board provide a benefit to user in terms of mobility.

\section{FUTURE ENHANCEMENT}

Augmented Reality based Commercial garment application board is enhanced later.

\subsection{Introduction to Augmented Reality:}

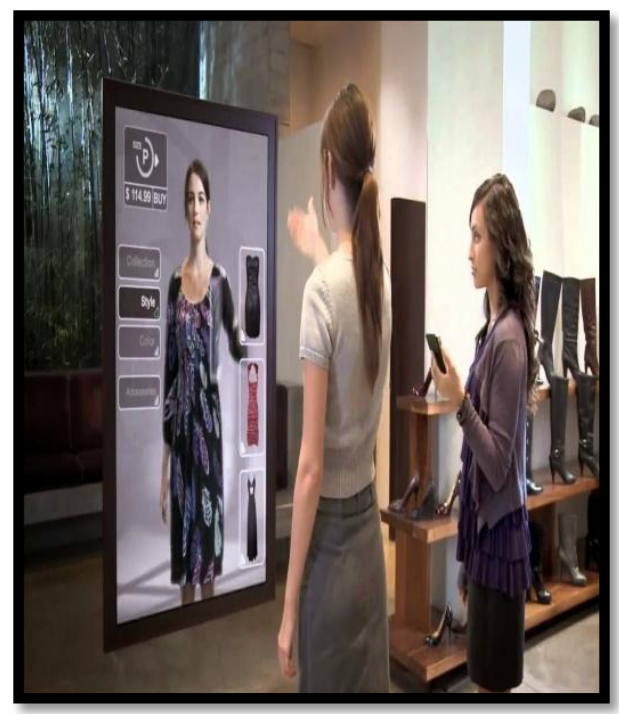

Fig: 5.1 Augmented reality
Augmented reality (AR) is a live direct or indirect view of a physical, real-world environment whose elements are augmented (or supplemented) by computer-generated sensory input such as sound, video, graphics or GPS data. It is related to a more general concept called mediated reality.

\section{REFERENCES}

[1] G.P.Rajesh Praveen raj Pattar M.N.Divya and Vara Prasad "Nfc field application" in 2016 IEEE International Conference on Communications (ICC) pp. 41-49 Dec 2016.

[2] Neeraj Khera Dhivya Shukla Shambhavi Awasthi "Development of simple and low cost Android based wireless notice board " in 2016 IEEE International Conferences on communications(ICC) pp. 19 December 2016

[3] W. D. Yu H. Hansrao K. Dhillon and P. Desinguraj “ Nfc based mhealthcare application focusing on security privacy and performance " in 2013 IEEE International Conference on Communications (ICC) pp. 4104 - 4109 June 2013.

[4] J. Fischer "Nfc in cell phones: The new paradigm for an interactive world [near-field communications] " IEEE Communications Magazine vol. 47 pp. 22 - 28 June 2009.

[5] N. Jagan Mohan Reddy et al. "Wireless electronic display board using GSM technology" <em>International Journal of Electrical Electronics and Data Communication $</ \mathrm{em}>$ vol. 1 no. 10 pp. $50-54$ 2013.

\section{BIOGRAPHIES}

Prof. Mr. A. John Paul Antony, M.E is affiliated to Kamaraj College of Engineering and Technology, Virudhunagar, India.

BalaNagammal $\mathbf{M}$ pursing her B.Tech. degree in the Department of Information Technology, Kamaraj College of Engineering and Technology, Virudhunagar, India.

Nilavarasi $\mathbf{S}$ pursing her B.Tech. degree in the Department of Information Technology, Kamaraj College of Engineering and Technology, Virudhunagar, India.

Priyanka $\mathbf{M}$ pursing her B.Tech. degree in the Department of Information Technology, Kamaraj College of Engineering and Technology, Virudhunagar, India. 